Review

\title{
Anthocyanin Biosynthesis in Apple Fruit
}

\author{
Chikako Honda ${ }^{* * * *}$ and Shigeki Moriya
}

Apple Research Station, Institute of Fruit Tree and Tea Science, NARO, Morioka 020-0123, Japan

\begin{abstract}
Anthocyanin accumulation is responsible for the red color of the skin and flesh of apple fruits (Malus $\times$ domestica Borkh.), and redder fruits are more marketable. Pigmentation in the skin of apple fruit varies among different cultivars and is influenced by environmental factors, including temperature conditions and the level of sunlight irradiation. Because warmer temperatures suppress anthocyanin synthesis in the skin of apple fruit, there are increasing concerns that global warming may be detrimental to fruit pigmentation. Recent molecular studies have revealed that the MdMYB1/10/110 a gene, which encodes a transcription factor, plays a critical role in regulating anthocyanin synthesis in both the skin and flesh of apple fruits. A markerassisted selection process has been developed to identify MdMYB1 genotypes and predict those fruits that will develop redder skin. These apples may be better adapted to a warmer global climate. The application of hormones can also increase the level of pigmentation in fruit skin, and plant growth regulators such as ethylene and jasmonate are commercially available. The mechanisms that regulate anthocyanin biosynthesis in the flesh of red-fleshed apple fruit appear to partially differ from those that function in the skin of red-skinned fruit. In the flesh of red-fleshed fruit, the pigment accumulates under dark conditions, whereas no anthocyanin is synthesized in the skin of bagged apple fruit. Conversely, in both red-skinned and red-fleshed apple fruits, warmer temperatures inhibit anthocyanin accumulation. Further studies on the regulation of anthocyanin synthesis in the flesh of red-fleshed apple fruit are necessary.
\end{abstract}

Key Words: environmental factors, flesh, MYB gene, red coloration, skin.

\section{Introduction}

The red pigmentation in the skin and flesh of apple fruits (Malus $\times$ domestica Borkh.) is due to anthocyanin accumulation. Anthocyanins belong to a class of molecules called flavonoids, and they are particularly important for fruit quality because redder fruits have a higher market value. Anthocyanin biosynthesis in the skin of apple fruit is suppressed at warmer temperatures, and poor pigmentation has already become a problem in some regions owing to global climate change (Iglesias et al., 2016). Recently, apples with red flesh have attracted increasing attention. In Japan, new red-fleshed apple cultivars with low acidity, including 'Ruby Sweet' and 'Rose Pearl', have been registered (Abe et al., 2017a, b). In addition, anthocyanins belong to a group of phenolic compounds that have antioxidant

Received; August 15, 2017. Accepted; December 29, 2017. First Published Online in J-STAGE on March 13, 2018.

* Corresponding author (E-mail: hondac@isas.a.u-tokyo.ac.jp).

** Present address: Graduate School of Agricultural and Life Sciences, The University of Tokyo, Nishitokyo 188-0002, Japan properties, and both white- and red-fleshed apple fruits are a major source of dietary antioxidants (Rupasinghe et al., 2010; Wojdyło et al., 2008). Therefore, the mechanisms that regulate anthocyanin accumulation in the fruit skin and flesh are of particular interest.

There have been a number of recent molecular biological studies on anthocyanin biosynthesis in the apple. In 2010, Velasco et al. published the whole genome sequence of the domesticated apple ('Golden Delicious') and reported that the apple genome had more biosynthetic genes (1246) involved in volatile, aromaticcompound, pigment, antioxidant, and sorbitol metabolite pathways than other higher plants (e.g., Arabidopsis, 719 genes; rice, 910 genes; grape, 1121 genes). Moreover, the identification of apple MYB transcription factor (TF) genes that play major roles in anthocyanin accumulation in apple fruit has led to significant advances in understanding the genetic basis of pigmentation (Ban et al., 2007; Chagné et al., 2007; Takos et al., 2006; Umemura et al., 2013). In contrast to red-skinned apples, red-fleshed cultivars are not widely produced, and little is known about their physiology. The aim of this review was to provide a brief overview 
of previous and recent research on anthocyanin biosynthesis in both the skin and flesh of apple fruits.

\section{Biosynthetic pathways in apple fruit}

\section{1) Anthocyanin biosynthesis and pigment composition}

The basic pathway for anthocyanin biosynthesis in higher plants is the same, although modification reactions that occur in some of the later steps differ among plant species (Mazza and Miniati, 1993). The anthocyanin pigment composition of apples is simple compared to that of other fruit crops (e.g., grapes and blueberries). In apple fruit skin, cyanidin (cya) 3-galactoside (gal) is the major pigment and it accounts for more than $85 \%$ of the anthocyanins present. The remaining pigments include cya 3 -arabinoside and cya 3 -glucoside, as well as some others. The cya 3-gal synthetic pathway is shown in Figure 1. The anthocyanin composition of apple fruit skin is similar among the different cultivars, although the appearance of the skin can differ. One reason for this is that apple skin color is also influenced by chlorophyll and carotenoid contents.

Some apples have red-fleshed fruit, and the anthocyanins in the red flesh are the same as those found in red skin (Mazza and Miniati, 1993). Cya 3-gal also predominates in the fruit flesh, but constitutes a lower proportion of the total anthocyanin content: $39 \%$ cya 3 -gal in Malus niedzwetzkyana (Mazza and Velioglu, 1992) and $68 \%$ in 'Weirouge' (Sadilova et al., 2006).

\section{2) Biosynthetic genes}

Many early studies that evaluated pigment accumulation in the skin of apple fruit measured the activity of enzymes of the anthocyanin biosynthetic pathway. They found that the activities of chalcone synthase (CHS), dihydroflavonol 4-reductase (DFR), and UDP:flavonoid 3-O-glycosyltransferase (UFGT) in the skin increased as anthocyanin was produced during fruit maturation (CHS and UFGT in 'Delicious' and 'Ralls' apples, Ju et al., 1995; DFR in 'Delicious' apples, Ju et al., 1997). Honda et al. (2002) reported that the expression of the structural genes underlying anthocyanin biosynthesis, including CHS, flavanone 3-hydroxylase $(F 3 H), D F R$, anthocyanidin synthase (ANS), and UFGT, was upregulated concomitant with increased anthocyanin accumulation in the skin of the 'Jonathan' and 'Fuji'. These five biosynthetic genes were also expressed at low levels in the yellow/green 'Orin' apple. Kondo et al. (2002) showed that in the yellow/green skin of mature sun-exposed 'Mutsu' apple fruit, $\mathrm{CHS}, \mathrm{F} 3 \mathrm{H}$, and $D F R$ were expressed, but $A N S$ and $U F G T$ were not. However, after the bags used to cover the 'Mutsu' apples were removed and the fruits were exposed to sunlight, the expression of the five biosynthetic genes was induced, and the fruits turned red. The expression of an MYB TF gene, MdMYB1, in the skin of the apple cultivar 'Jonathan' also increased prior to harvest and in parallel with pigmentation (Ban et al., 2007). Therefore,

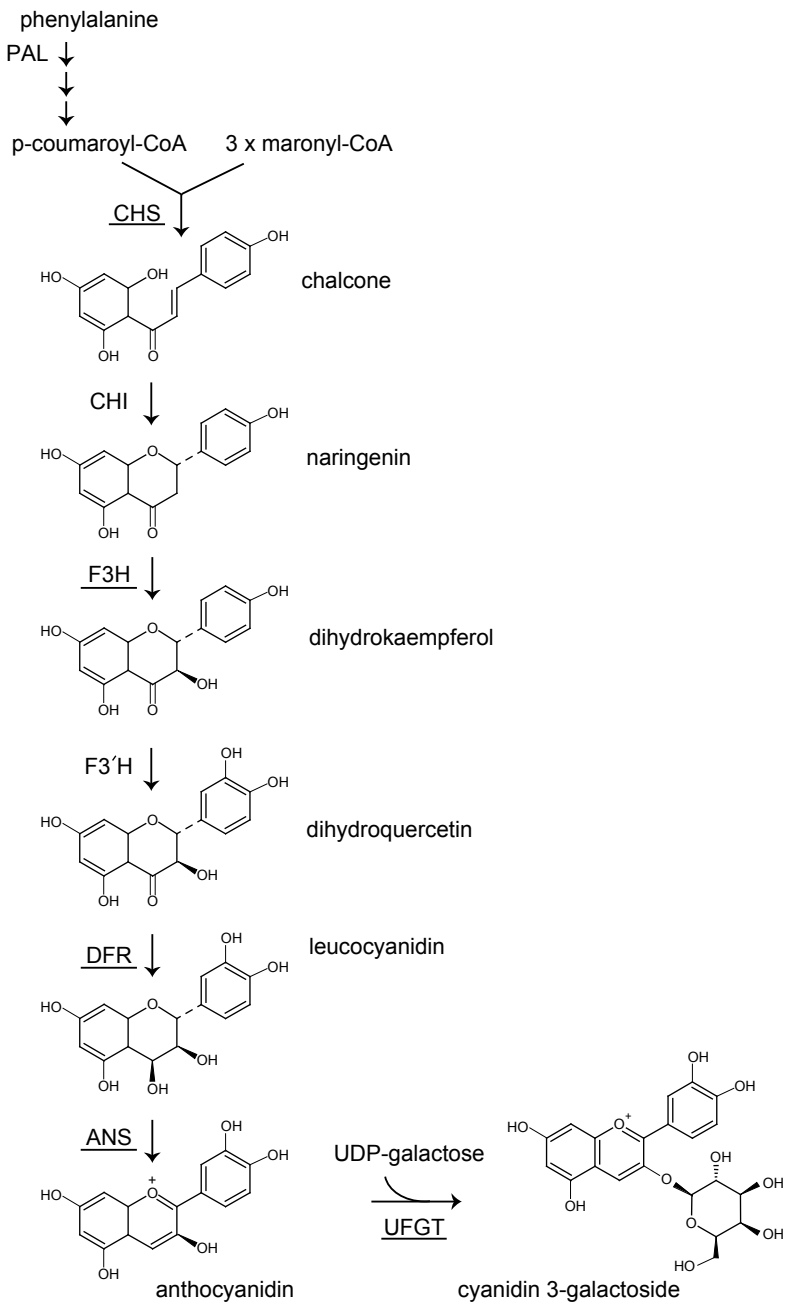

Fig. 1. The anthocyanin biosynthesis pathway in apple fruits. The synthesis of cyanidin 3-galactoside is shown. The reactions in the pathway are catalyzed by PAL, phenylalanine ammonia lyase; $\mathrm{CHS}$, chalcone synthase; $\mathrm{CHI}$, chalcone isomerase; $\mathrm{F} 3 \mathrm{H}$, flavanone 3-hydroxylase; F3'H, flavonoid 3'-hydroxylase; DFR, dihydroflavonol 4-reductase; ANS, anthocyanidin synthase; and UFGT, UDP:flavonoid 3-O-glycosyltransferase. The expression of the genes encoding the underlined enzymes was analyzed by Northern blotting, and the results are shown in Figure 2.

the regulation of anthocyanin biosynthesis-related gene expression may determine the amount of pigmentation in the skin of apple fruit. In contrast, for apple fruit flesh, Umemura et al. (2013) reported that an MYB TF gene, MdMYB110a, CHS, and ANS genes reached their maximal expression in the red flesh of 'JPP35' apple fruit at approximately 40 days before harvest. Sato et al. (2017) also demonstrated that MdMYB110a in the red flesh of 'Nakano Shinku' and 'Nakano no Kirameki' apples reached its maximal expression at 30 days before harvest. By this time, anthocyanin had already begun to accumulate in 'Nakano Shinku', but not in 'Nakano no Kirameki' apples. In addition, in the flesh of the 'Nakano Shinku' apple, the expression of $C H S$, chalcone isomerase $(C H I), D F R, A N S$, and UFGT peaked at 
30 days before harvest, whereas in 'Nakano no Kirameki' apple flesh, these genes (with the exception of $C H S$ ) were expressed at low levels at 30 days before harvest, but at higher levels toward maturity. These results indicate that anthocyanin accumulation and the expression of biosynthesis-related genes do not coincide in red-fleshed 'Nakano Shinku' apple fruit.

\section{Factors that influence anthocyanin synthesis in apple fruit skin}

\section{1) Genetic factors}

Apples have the complete set of genes required to synthesize anthocyanin and its precursors. The regulation of these genes determines the color of the fruit skin. Cheng et al. (1996) identified a sequence tagged site (STS) marker derived from the random amplified polymorphic DNA marker that could predict fruit skin color (red/yellow) in apples, and they advocated that the red skin color was primarily controlled by one or more dominant genes at a single locus, $\mathrm{R} f$. Later, genetic mapping using a linkage map constructed from the 'Delicious' $\times$ 'Mitsubakaido' (Malus sieboldii) cross; an expression analysis in the 'Cripp's Red', 'Jonathan', and 'Tsugaru'; and functional characterization using
Arabidopsis thaliana, Nicotiana tabacum, and apple cotyledons revealed that the red pigmentation of apple fruit skin depends on the genotypes of a key R2R3 MYB gene called MdMYB1 (Ban et al., 2007; Takos et al., 2006). MdMYB1 is located on the distal end of chromosome 9 and is responsible for fruit skin color, whereas $M d M Y B 10$, an allele of MdMYB1 (Lin-Wang et al., 2010), confers red flesh, foliage, and stems, as well as red fruit skin (Ban et al., 2007; Takos et al., 2006). Although MdMYB10 also affects skin color, only $M d M Y B 1$ is considered in this section. Flanking polymorphic markers showed that there were at least four MdMYB1 alleles (Moriya et al., 2017; Yuan et al., 2014; Zhu et al., 2011), three of which were sequenced (MdMYB1-1, MdMYB1-2, and MdMYB1-3) (Takos et al., 2006). Although the three translational products did not differ functionally, MdMYB1-1 was the only allele associated with red skin color (Table 1). The other two alleles did not confer red skin under normal circumstances owing to their low expression (Takos et al., 2006). Methylation in the $M d M Y B 1$ promoter region in bud sports of 'Gala' and in bagged 'Mutsu' fruit suggested that epigenetic regulation was important in the expression of the MdMYB1 gene (Bai et al., 2016;

Table 1. Relationship between $M d M Y B 1$ genotypes and fruit skin color in major apple cultivars.

\begin{tabular}{lccll}
\hline \hline \multicolumn{1}{c}{ Apple cultivar } & Fruit skin color & MdMYB $1^{\mathrm{z}}$ & $\mathrm{Mdo} . \mathrm{chr} 9.4^{\mathrm{y}}$ & Triploid \\
\hline Akane & Red & $1 / 1$ & $\mathrm{R}_{0} / \mathrm{R}_{0}$ & \\
Akibae & Red & $1 / 1$ & $\mathrm{R}_{0} / \mathrm{R}_{0}$ & \\
Braeburn & Red & $1 / 2$ & $\mathrm{R}_{0} / \mathrm{Y}_{-3}$ & \\
Cox's Orange Pippin & Red & $1 / 2$ & $\mathrm{R}_{0} / \mathrm{Y}_{-3}$ & \\
Elstar & Red & $1 / 2$ & $\mathrm{R}_{0} / \mathrm{Y}_{-3}$ & \\
Fuji & Red & $1 / 3$ & $\mathrm{R}_{0} / \mathrm{Y}_{-15}$ & \\
Gala & Red & $1 / 2$ & $\mathrm{R}_{0} / \mathrm{Y}_{-3}$ & $\checkmark$ \\
Hokuto & Red & $1 / 2 / 3$ & $\mathrm{R}_{0} / \mathrm{Y}_{-3} / \mathrm{Y}_{-15}$ & $\checkmark$ \\
Jonagold & Red & $1 / 2 / 3$ & $\mathrm{R}_{0} / \mathrm{Y}_{-3} / \mathrm{Y}_{-15}$ & \\
Jonathan & Red & $1 / 1$ & $\mathrm{R}_{0} / \mathrm{R}_{0}$ & \\
McIntosh & Red & $1 / 2$ & $\mathrm{R}_{0} / \mathrm{Y}_{-3}$ & \\
Mutsu & Red & $1 / 2$ & $\mathrm{R}_{0} / \mathrm{Y}_{-3}$ & \\
Ralls Janet & Red & $1 / 1$ & $\mathrm{R}_{0} / \mathrm{R}_{0}$ & \\
Redgold & Red & $1 / 3$ & $\mathrm{R}_{0} / \mathrm{Y}_{-15}$ & \\
Ruby Sweet & Red & $1 / 3$ & $\mathrm{R}_{0} / \mathrm{Y}_{-15}$ & \\
Sensyu & Red & $1 / 3$ & $\mathrm{R}_{0} / \mathrm{Y}_{-15}$ & \\
Shinano Sweet & Red & $1 / 1$ & $\mathrm{R}_{0} / \mathrm{R}_{0}$ & \\
Starking Delicious & Red & $1 / 3$ & $\mathrm{R}_{0} / \mathrm{Y}_{-15}$ \\
Tsugaru & Red & $1 / 2$ & $\mathrm{R}_{0} / \mathrm{Y}_{-3}$ \\
Worcester Pearmain & Red & $1 / 1$ & $\mathrm{R}_{0} / \mathrm{R}_{0}$ \\
Golden Delicious & Yellow & $2 / 3$ & $\mathrm{Y}_{-3} / \mathrm{Y}_{-15}$ \\
Granny Smith & Green & $2 / 4$ & $\mathrm{Y}_{-3} / \mathrm{Y}_{-9}$ \\
Indo & Green & $2 / 2$ & $\mathrm{Y}_{-3} / \mathrm{Y}_{-3}$ & \\
Orin & Yellow & $2 / 3$ & $\mathrm{Y}_{-3} / \mathrm{Y}_{-15}$ & \\
Shinano Gold & Yellow & $2 / 3$ & $\mathrm{Y}_{-3} / \mathrm{Y}_{-15}$ & \\
Rose Pearl & Yellow & $3 / 3$ & $\mathrm{Y}_{-15} / \mathrm{Y}_{-15}$ & \\
\hline
\end{tabular}

${ }^{z}$ MdMYB1 genotype estimated from Mdo.chr9.4 genotypes.

y A simple sequence repeat marker developed from MdMYB1 DNA $16 \mathrm{kbp}$ downstream of the transcription start site (Moriya et al., 2017). Only $\mathrm{R}_{0}$ associated with $M d M Y B 1-1$ confers red fruit skin. 
El-Sharkawy et al., 2015). Following translation, MYB $\mathrm{TF}$ coordinately regulates biosynthetic gene expression with a basic helix-loop-helix protein (bHLH) and a WD-repeat protein (WDR; Gonzalez et al., 2008). The genes encoding bHLH and WDR have been isolated in the apple (An et al., 2012; Xie et al., 2012).

An MYB TF gene, which had an inhibitory effect on anthocyanin biosynthesis in fruit, was isolated in the strawberry, which belongs to the same family as the apple (Rosaceae) (Salvatierra et al., 2013). The apple MdMYB6 gene inhibited anthocyanin accumulation when overexpressed in transgenic Arabidopsis (Gao et al., 2011), but its function could not be confirmed in the apple.

In many different apple accessions, $M d M Y B 1-1$ has a dominant effect on fruit skin color. Apples that are heterozygous or homozygous for MdMYB1-1 have redskinned fruit, whereas those that have no MdMYB1-1 copy are yellow or green. Ban et al. (2007) suggested that the $\mathrm{A}^{1}$ (associated with red skin color), $\mathrm{a}^{1}$ (associated with yellow skin color), and $\mathrm{a}^{2}$ (associated with yellow skin color) alleles of the STS marker reported by Cheng et al. (1996) correspond to MdMYB1-1, $M d M Y B 1-2$, and MdMYB1-3, respectively, from the results of MdMYB1 mapping. An association analysis of 160 apple accessions determined that MdMYB1-1 had an incomplete dominant effect on fruit skin color (Fig. 2; Moriya et al., 2017). In addition, a quantitative trait locus (QTL) analysis using an $\mathrm{F}_{1}$ population derived from an 'Orin' $\times$ 'Akane' cross identified a QTL for skin color at the MdMYB1 locus in the MdMYB1-1 homozygote 'Akane,' which suggests an unknown allelic variation even within MdMYB1-1 (Kunihisa et al., 2014). Other than $M d M Y B 1$, no firm QTL which controls skin color has been reported.

Several DNA markers discriminate $M d M Y B 1-1$ from others (Chagné et al., 2016; Moriya et al., 2017; Takos et al., 2006; Yuan et al., 2014; Zhang et al., 2014). At the moment, Mdo.chr9.4 (Moriya et al., 2017), a simple sequence marker developed $16 \mathrm{kbp}$ downstream from the transcription start site of $M d M Y B 1$ is thought to be the best marker to correctly distinguish $M d M Y B 1$ alleles.

More recently, $\mathrm{Hu}$ et al. (2016) demonstrated that MdMYB1 elevated the expression of proton pump genes encoding a vacuolar $\mathrm{H}^{+}$-ATPase (VHA) and/or vacuolar $\mathrm{H}^{+}$-pyrophosphatase via overexpression of MdMYB1 by agrobacterium-mediated transformation in apple calli ('Orin') and also via a transient expression of the genes in apple peel ('Red Delicious'). They also showed that the anthocyanin and malate contents increased, but the $\mathrm{pH}$ decreased, in the transformed tissues, which indicates that MdMYB1 may directly regulate not only anthocyanin biosynthesis in the fruit skin, but also vacuolar transport, thereby affecting both the color and $\mathrm{pH}$ in the cells.

\section{2) Environmental factors}

Sunlight irradiation is one of the most important environmental factors that stimulates anthocyanin biosynthesis in apple fruit skin (Ubi, 2004). No anthocyanin was synthesized in the skin of apple fruits kept under dark conditions ('Tsugaru', 'Jonathan', 'Jonagold', and 'Fuji'; Arakawa, 1991). Because fruit skin shaded by leaves produces little pigment, the leaves are removed prior to harvesting (Iwanami et al., 2016). Ju et al. (1999) demonstrated that covering the ground of an orchard with a reflective film enhanced color development in the skin of 'Fuji' apple fruit. Vimolmangkang et al. (2014) used microarray analysis to demonstrate that 'Red Delicious' apple fruit exposed to sunlight had higher levels of anthocyanin biosynthetic gene expression than those in dark-grown fruits, and that genes in dark-grown fruits were expressed after a 14-h exposure to daylight.

Temperature also has a significant influence on anthocyanin biosynthesis in apple fruit skin (Ubi, 2004). Cooler climatic conditions stimulate anthocyanin biosynthesis, whereas warmer temperatures suppress pigment development. Therefore, anthocyanin accumulation in the skin of apple fruit may be affected by increasing global warming. Iglesias et al. (2002) reported that an irrigation cooling system comprising an overtree microsprinkler improved the reddening of 'Topred Delicious' apple fruit. Ubi et al. (2006) showed that a simultaneous treatment with light irradiation in the UV-B region (wavelength from 280 to $320 \mathrm{~nm}$ ) and low temperature $\left(17^{\circ} \mathrm{C}\right)$ for 5 days enhanced anthocyanin accumulation and the expression of biosynthetic genes in the skin of bagged apple fruits ['American Summer Pearmain' (syn. Iwai), 'Sansa', 'Tsugaru', 'Homei-Tsugaru', and 'Akane'; Fig. 3]. High temperature conditions suppressed anthocyanin accumulation and the expression of associated biosynthetic and TF genes in the skin of apple fruits that were still on the tree ('Gala'; Lin-Wang et al., 2011). Honda et al. (2014) also demonstrated that anthocyanin synthesis in the skin of 'Misuzu-Tsugaru' apple fruit was suppressed when trees were grown in a greenhouse where the temperature was increased by $4^{\circ} \mathrm{C}$ for the 5 months immediately prior to harvesting.

\section{3) Plant hormones}

Ethylene production in apple fruit increases toward harvest and stimulates anthocyanin biosynthesis in fruit skin. Whale and Singh (2007) reported that ethylene production in 'Pink Lady' apple fruit increased as anthocyanin accumulated in the fruit skin. Ethephon (2chloroethylphophonic acid) is a growth regulator that is converted into ethylene in the plant; it is used commercially to enhance apple color (Saure, 1990). Larrigaudiere et al. (1996) showed that applying ethephon to 'Starking Delicious' fruit 2 weeks before commercial harvest increased the concentration of 
anthocyanin in the fruit skin. Because ethylene stimulates fruit ripening, ethephon treatment not only improves skin color, but also softens the fruit (Wang and Dilley, 2001). In higher plants, ethylene binds to a receptor that acts as a negative regulator of signal transduction pathways controlling ripening and senescence. Ireland et al. (2012) reported that the apple genome contains nine ethylene receptor genes. However, it is not known how ethylene signaling stimulates anthocyanin synthesis in the skin of apple fruit.

Jasmonate (JA) and its derivatives can also generate pigmentation in the skin of apple fruit. Rudell et al. (2005) showed that applying methyl JA to 'Fuji' apples before harvest induced anthocyanin biosynthesis in the fruit skin. Prohydrojasmon, a synthetic JA, is commer-

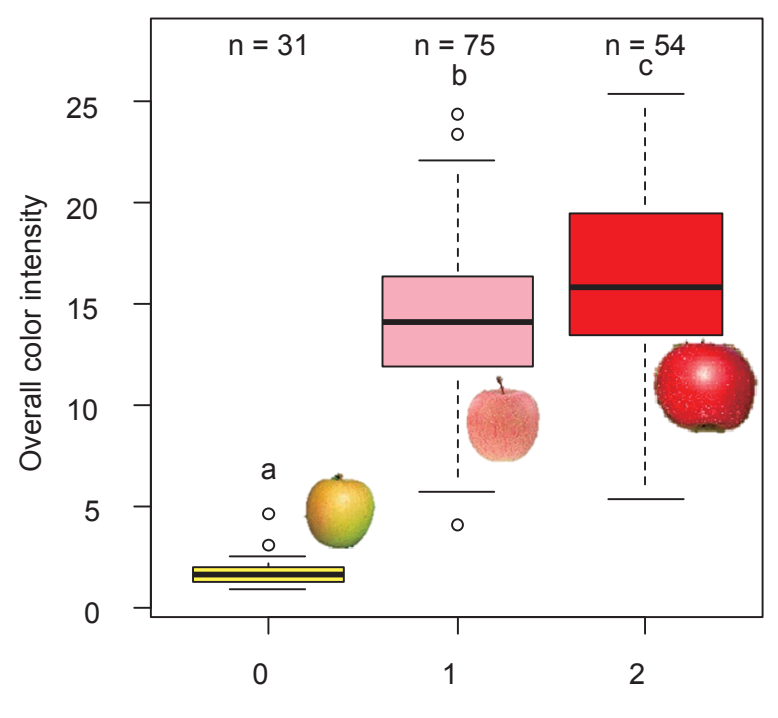

Copy number of the Mdo.chr9.4- $\mathrm{R}_{0}$ allele

Fig. 2. Relationship between fruit skin color and simple sequence repeat marker Mdo.chr9.4 genotypes from 160 apple accessions. Skin color was quantified as overall color intensity, which is the depth/shade of color over a given area of the fruit skin. Each accession was assessed over an average period of 7.14 years. Different letters indicate significant differences determined using the Steel-Dwass test $(P<0.05)$.
A

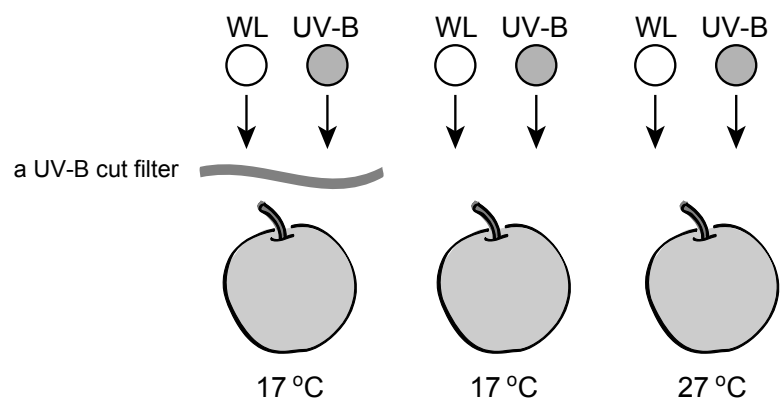

B
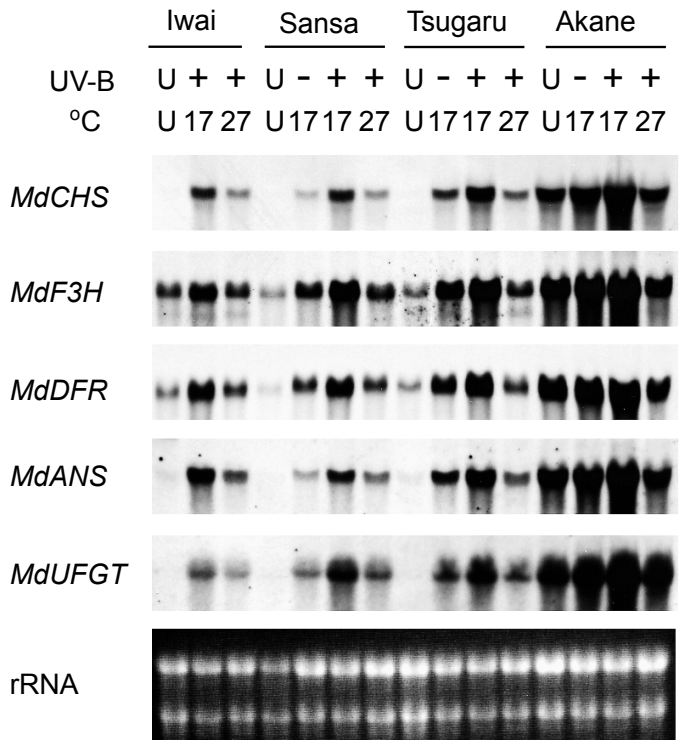

Fig. 3. Synergistic effects of UV-B and low temperature on stimulating the expression of anthocyanin biosynthetic genes. A. Schematic representation of the experimental design, including UV-B and temperature treatments. For the treatment without UV-B irradiation, a filter that did not transmit UV-B was used. WL, illumination with white light; UV-B, irradiation with UVB. B. The expression of five anthocyanin biosynthetic genes in the fruit skin from four early-ripening apple cultivars was analyzed by Northern blotting. $\mathrm{U}$, untreated fruit. Parts of the $D F R$ and $U F G T$ gene sequences were used to make probes. The figure is adapted from Ubi et al. (2006).
A

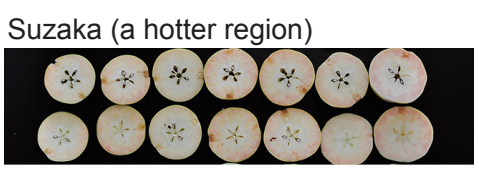

Morioka (a cooler region)

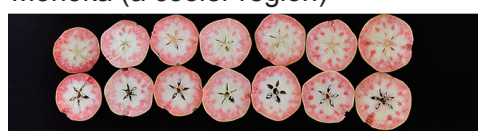

B

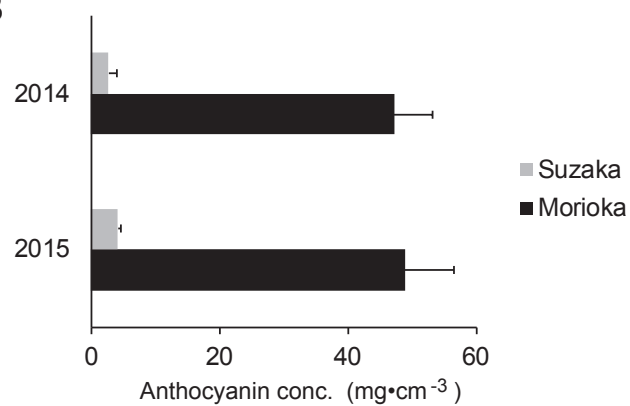

Fig. 4. The red flesh of 'Pink Pearl' apples from two different growing regions. A. The apples shown were harvested at Suzaka $\left(36^{\circ} 7^{\prime} \mathrm{N}\right.$, $138^{\circ} 3^{\prime} \mathrm{E}, 363 \mathrm{~m}$ altitude) and Morioka $\left(39^{\circ} 8^{\prime} \mathrm{N}, 141^{\circ} 1^{\prime} \mathrm{E}, 193 \mathrm{~m}\right.$ altitude) in 2015. B. Anthocyanin concentration in the apple flesh. Different letters indicate significant differences determined using the Tukey-Kramer method $(P<0.05)$. The figure is adapted from Honda et al. (2017). 
cially available as a plant growth regulator (Koshiyama et al., 2003). JAs mediate responses to wounding, and their capacity to stimulate pigmentation may be related to this role (Creelman and Mullet, 1997). An et al. (2015) reported that the expression of the MYB TF genes $M d M Y B 9$ and $M d M Y B 11$ increased significantly compared to that of $M d M Y B 1$ in 'Orin' apple calli in response to JA treatment and in 'Gala' leaves in response to wounding. Subsequent functional analyses demonstrated that these two MYB TFs bound to the promoter regions of some flavonoid biosynthetic genes and induced anthocyanin accumulation in calli in the presence of JA.

Few reports have focused on plant hormones other than ethylene and JA. Ben-Arie et al. (1971) showed that applying the synthetic auxins naphthaleneacetic acid and 2,4,5-trichrolophenoxypropionic acid at 1 month before harvest promoted anthocyanin synthesis in the skin of apple fruits of 'Gallia Beauty', 'Jonathan', and 'Starking Delicious'. Recently, Stern et al. (2010) reported that the red color of 'Cripp's Pink' apples could be enhanced by applying the synthetic auxin 2,4-dichrolophenoxypropionic acid (2,4-D) to young fruitlets 60 days after full bloom. Skin color improvement following auxin treatment is considered to be a result of advancing maturity caused by ethylene production because the auxins promote ethylene production in the fruit. Iamsub et al. (2009) demonstrated that applying abscisic acid produced a redder skin in 'Tsugaru' and 'Sensyu' apple fruits. However, there is no consensus of opinion regarding the relationship between abscisic acid and anthocyanin synthesis in the skin of apple fruit, and further research is required.

\section{4) Nutrition}

An adequate supply of nitrogen $(\mathrm{N})$ is essential for high yields of good-quality apple fruit. However, applying excessive amounts of $\mathrm{N}$ to apple trees suppresses anthocyanin accumulation in fruit skin. Boynton and Burrell (1944) demonstrated that supplying an excess of $\mathrm{N}$ increased yields, but generated a softer 'McIntosh' apple fruit with a poor color. More than half a century later, a fertigation experiment by Neilsen et al. (2009) using five apple cultivars ('Ambrosia', 'Cameo', 'Fuji', 'Gala', and 'Silken') during the first six fruiting seasons demonstrated that high $\mathrm{N}$ treatment decreased red color quality at a high crop load, but not the cumulative yield. Wang and Cheng (2011) reported that an excess of $\mathrm{N}$ decreased anthocyanin biosynthesis and chlorophyll degradation in the skin of 'Gala' apple fruit and suggested that increased $\mathrm{N}$ treatment may promote more vigorous shoot growth and thereby reduce anthocyanin biosynthesis by decreasing exposure to light.

\section{Factors that influence anthocyanin biosynthesis in apple fruit flesh}

\section{1) Genetic factors}

MYB TFs MdMYB10 and MdMYB110a play important roles in generating red flesh in apple fruit (Chagné et al., 2007, 2013; Umemura et al., 2013; Volz et al., 2013). MdMYB10, an allele of MdMYB1 (Lin-Wang et al., 2010), is located on chromosome 9 and generates red flesh, designated as type 1. MdMYB110a is located on chromosome 17 and generates red flesh, designated as type 2. The chromosomal locations of these genes suggest that they originated from an ancient duplication event during the evolution of the Maloideae subfamily (Chagné et al., 2013). The two genes share approximately $66 \%$ identity at the amino acid level (Umemura et al., 2013). In type 1 red flesh apples, MdMYB10 confers extensive anthocyanin accumulation throughout the plant, including fruit flesh and skin, flowers, leaves, and stems. In type 2 apples, only the flesh is red, and other organs are the same color as those of common apple trees that bear white-fleshed fruit. Therefore, fruits with yellow skin and red flesh are only associated with the MdMYB110a genotype (Table 2). MdMYB10 and $M d M Y B 110 a$ are expressed early and late in the fruit maturation process, respectively (Hamada et al., 2015).

The promoter region of MdMYB10 has six MYB binding motifs in tandem, whereas other MdMYB1 alleles have a single MYB binding motif at the promoter (Espley et al., 2009). Therefore, MdMYB10 and other MdMYB1 alleles are known as R6 and R1 MYBs, respectively. The tandem motif in MdMYB10 positively regulates its own expression, which results in an abun-

Table 2. MYB genes responsible for red flesh in apples.

\begin{tabular}{lccc}
\hline \hline \multicolumn{1}{c}{ Apple accession } & Gene responsible for red flesh & Reference \\
\hline Malus niedzwetzkyana & MdMYB10 & Fruit skin color & Espley et al. (2009) \\
Geneva & MdMYB10 & Red & Espley et al. (2009) \\
Maypole & MdMYB10 & Red & Ban et al. (2007) \\
Red Field & MdMYB10 & Espley et al. (2009) \\
Pink Pearl & MdMYB110a & Red & Chagné et al. (2013) \\
Rose Pearl & MdMYB110a & Yellow & Abe et al. (2017) \\
Ruby Sweet & MdMYB110a & Yellow & Abe et al. (2018) \\
JPP35 & $M d M Y B 110 a$ & Red & Umemura et al. (2013) \\
\hline
\end{tabular}

${ }^{z}$ Red flesh is caused by MdMYB10 (type 1) and MdMYB110a (type 2). 
dance of MdMYB10 and anthocyanin accumulation in many different organs. In contrast, the molecular mechanisms that regulate $M d M Y B 110 a$ expression are unclear. The presence of both MdMYB10 and $M d M Y B 110 a$ in any single plant proved difficult to confirm, and an attempt to generate a new red-fleshed cultivar containing both genes by crossing 'Geneva' (type 1) and 'Pink Pearl' (type 2) failed, leading Hamada et al. (2015) to suggest that breeding depression had occurred.

A DNA marker to detect the unique R6 minisatellite sequence was developed for the MdMYB10 gene (Espley et al., 2009). For MdMYB110a, two independent single nucleotide polymorphisms in the exon 2 were subjected to a detection system employing either a high-resolution melting-based marker or a derived cleaved amplified polymorphic sequence marker (Chagné et al., 2013; Sato et al., 2017). These DNA markers could be useful for the efficient breeding of red-fleshed apple cultivars.

\section{2) Environmental factors}

Sunlight irradiation is not crucial for anthocyanin biosynthesis in the red flesh of some apple cultivars, in contrast to fruit skin. For example, bagged fruits of 'Geneva' and 'Pink Pearl' accumulated approximately $70 \%$ of the total anthocyanin content found in fruits of the same cultivars exposed to sunlight (Honda et al., 2017). However, sunlight irradiation is required to maximize anthocyanin accumulation in the flesh of fruits from both cultivars.

The temperature during fruit ripening is an important factor in anthocyanin synthesis in apple fruit flesh, as is the case in the fruit skin. In Japan, the early-ripening 'Pink Pearl' apple is usually harvested at Suzaka in late August (mean annual air temperature, $11.9^{\circ} \mathrm{C}$ ) and at Morioka in early September (mean annual air temperature, $10.2^{\circ} \mathrm{C}$ ). In 2014 and 2015 , anthocyanin concentrations in the flesh of 'Pink Pearl' apples harvested at Morioka were more than 10-fold higher than those in apples harvested at Suzaka (Fig. 4; Honda et al., 2017). The anthocyanin concentrations in the flesh of mature 'Pink Pearl' fruit harvested at Morioka in 2016 were considerably lower than those measured in the average year $\left(10.3 \mu \mathrm{g} \cdot \mathrm{cm}^{-3}\right.$ compared to approximately $50 \mu \mathrm{g} \cdot \mathrm{cm}^{-3}$ ), probably because of the high temperatures recorded during late August in 2016 (Honda et al., unpublished data). As is the case for common apples with red skin and white flesh, growth under full sunlight conditions and cool temperatures may be required to maximize anthocyanin content in red-fleshed apple fruit.

\section{3) Other factors}

There have been few studies on the effects of plant hormones on anthocyanin accumulation in the flesh of red-fleshed apple fruit. Ji et al. (2015) investigated the effects of auxin treatment on anthocyanin biosynthesis in calli derived from leaves of the red-fleshed apple M. niedzwetzkyana (type 1). They found that adding 1naphthalene acetic acid and 2,4-D to the growth media inhibited anthocyanin production and downregulated the expression of anthocyanin biosynthetic and related TF genes in the calli. In contrast, Ben-Arie et al. (1971) and Stern et al. (2010) found that auxin stimulated anthocyanin production in the apple fruit skin. Subsequently, Sun et al. (2017) demonstrated that methyl JA treatment enhanced anthocyanin synthesis in calli, whereas anthocyanin accumulation was inhibited by adding abscisic acid. The inductive effect of methyl JA in calli is consistent with that observed in previous studies on fruit skin (Rudell et al., 2005), whereas the effects of abscisic acid treatment on calli and fruit skin may differ (Iamsub et al., 2009). These results indicate that anthocyanin biosynthesis in apple tissues is regulated in different ways by MdMYB10 and MdMYB1. Future research on the effects of plant hormones on anthocyanin biosynthesis in the flesh of red-fleshed apple fruit is required.

\section{Conclusions and Perspectives}

Recent research has indicated that the orthologs of molecular components identified in other higher plants may function in the anthocyanin biosynthetic pathway in the skin of apple fruit in addition to MYB-bHLHWDR complexes. MdHY5 and MdCOL11 were shown to be involved in regulating anthocyanin biosynthesis in apple fruit skin in response to light and/or low temperature (An et al., 2017; Bai et al., 2014; Peng et al., 2013). $\mathrm{Li}$ et al. (2012) demonstrated that MdCOP1 negatively regulated anthocyanin biosynthesis in the skin of apple fruit by modulating the degradation of MdMYB1, whereas Peng et al. (2013) reported that MdCOP1 activated MdHY5 signaling, which stimulated pigment formation in the fruit skin. MdJAZ2 and MdMYC2 were shown to be involved in mediating JA-stimulated anthocyanin biosynthesis in the skin of apple fruit (An et al., 2015, 2016). However, how these signaling components coordinately regulate the level of anthocyanin accumulation in the skin of apple fruit and how they generate differences in skin color among the different apple cultivars remain unclear. A marker-assisted selection procedure that enables breeders to effectively screen individuals for apples with redder skin using MdMYB1 genotypes has been developed (Moriya et al., 2017), and this procedure will facilitate the development of new apple cultivars with redder skin that may be better adapted to a warmer global climate. Concurrently, breeding programs for red-fleshed apple cultivars with good eating quality are underway worldwide (Abe et al., 2017a, b; Volz et al., 2009). Therefore, future studies should focus on the physiology and cultivation of apples with red flesh. 


\section{Literature Cited}

Abe, K., J. Soejima, H. Iwanami, N. Kotoda, S. Moriya, H. Bessho, S. Komori, Y. Ito, S. Takahashi, K. Okada, H. Kato, T. Haji, M. Ishiguro. 2018. New apple cultivar 'Ruby Sweet'. Bull. NARO Inst. Fruit Tree Tea Sci. 2: 9-17 (In Japanese with English abstract).

Abe, K., J. Soejima, H. Iwanami, N. Kotoda, S. Moriya, H. Bessho, S. Komori, Y. Ito, S. Takahashi, K. Okada, H. Kato, T. Haji, M. Ishiguro, T. Masuda and S. Tsuchiya. 2017. New apple cultivar 'Rose Pearl'. Bull. NARO Inst. Fruit Tree Tea Sci. 1: 9-18 (In Japanese with English abstract).

An, J., H. Li, L. Song, L. Su, X. Liu, C. You, X. Wang and Y. Hao. 2016. The molecular cloning and functional characterization of MdMYC2, a bHLH transcription factor in apple. Plant Physiol. Biochem. 108: 24-31.

An, J., F. Qu, J. Yao, X. Wang, C. You, X. Wang and Y. Hao. 2017. The bZIP transcription factor MdHY5 regulates anthocyanin accumulation and nitrate assimilation in apple. Hortic. Res. 4: 17023.

An, X., Y. Tian, K. Chen, X. Liu, D. Liu, X. Xie, C. Cheng, P. Cong and Y. Hao. 2015. MdMYB9 and MdMYB11 are involved in the regulation of the JA-induced biosynthesis of anthocyanin and proanthocyanidin in apples. Plant Cell Physiol. 56: 650-662.

An, X., Y. Tian, K. Chen, X. Wang and Y. Hao. 2012. The apple WD40 protein MdTTG1 interacts with bHLH but not MYB proteins to regulate anthocyanin accumulation. J. Plant Physiol. 169: 710-717.

Arakawa, O. 1991. Effect of temperature on anthocyanin accumulation in apple fruit as affected by cultivars, stages of fruit ripening and bagging. J. Hort. Sci. 66: 763-768.

Bai, S., T. Saito, C. Honda, Y. Hatsuyama, A. Ito and T. Moriguchi. 2014. An apple B-box protein gene, MdCOL11, is involved in UV-B- and temperature-induced anthocyanin biosynthesis. Planta 240: 1051-1062.

Bai, S., P. A. Tuan, T. Saito, C. Honda, Y. Hatsuyama, A. Ito and T. Moriguchi. 2016. Epigenetic regulation of MdMYB1 is associated with paper bagging-induced red pigmentation of apples. Planta 244: 573-586.

Ban, Y., C. Honda, Y. Hatsuyama, M. Igarashi, H. Bessho and T. Moriguchi. 2007. Isolation and functional analysis of a MYB transcription factor gene that is a key regulator for the development of red coloration in apple skin. Plant Cell Physiol. 48: 958-970.

Ben-Arie, R., D. Ga'ash, S. Guelfat-Reich and S. Lavee. 1971. The effects of growth regulators for the prevention of preharvest drop on the keeping quality of stored apples in the subtropical zone. J. Hort. Sci. 46: 131-145.

Boynton, D. and A. B. Burrell. 1944. Effects of nitrogen fertilizer on leaf nitrogen, fruit color and yield in two New York 'McIntosh' apple orchards, 1942 and 1943. Proc. Amer. Soc. Hort. Sci. 44: 25-30.

Chagné, D., C. M. Carlisle, C. Blond, R. K. Volz, C. J. Whiteworth, N. C. Oraguzie, R. N. Crowhurst, A. C. Allan, R. V. Espley, R. P. Hellens and S. E. Gardiner. 2007. Mapping a candidate gene (MdMYB10) for red flesh and foliage colour in apple. BMC Genomics 8: 212.

Chagné, D., C. Kirk, N. How, C. Whitworth, C. Fontic, G. Reig, G. Sawyer, S. Rouse, L. Poles and S. E. Gardiner. 2016. A functional genetic marker for apple red skin coloration across different environments. Tree Genet. Genomes 12: 19.

Chagné, D., K. Lin-Wang, R. V. Espley, R. K. Volz, N. M. How,
S. Rouse, C. Brendolise, C. M. Carlisle, S. Kumar, N. De Silva, D. Micheletti, T. McGhie, R. N. Crowhurst, R. D. Storey, R. Velasco, R. P. Hellens, S. E. Gardiner and A. C. Allan. 2013. An ancient duplication of apple MYB transcription factors is responsible for novel red fruit-flesh phenotypes. Plant Physiol. 161: 225-239.

Cheng, F. S., N. F. Weeden and S. K. Brown. 1996. Identification of co-dominant RAPD markers tightly linked to fruit skin color in apple. Theor. Appl. Genet. 93: 222-227.

Creelman, R. A. and J. E. Mullet. 1997. Biosynthesis and action of jasmonates in plants. Annu. Rev. Plant Physiol. Plant Mol. Biol. 48: 355-381.

El-Sharkawy, I., D. Liang and K. Xu. 2015. Transcriptome analysis of an apple (Malus $\times$ domestica) yellow fruit somatic mutation identifies a gene network module highly associated with anthocyanin and epigenetic regulation. J. Exp. Bot. 66: 7359-7376.

Espley, R. V., C. Brendolise, D. Chagné, S. Kutty-Amma, S. Green, R. Volz, J. Putterill, H. J. Schouten, S. E. Gardiner, R. P. Hellens and A. C. Allan. 2009. Multiple repeats of a promoter segment causes transcription factor autoregulation in red apples. Plant Cell 21: 168-183.

Gao, J., X. Shen, Z. Zhang, R. Peng, A. Xiong, J. Xu, B. Zhu, J. Zheng and Q. Yao. 2011. The myb transcription factor MdMYB6 suppresses anthocyanin biosynthesis in transgenic Arabidopsis. Plant Cell Tiss. Organ Cult. 106: 235-242.

Gonzalez, A., M. Zhao, J. M. Leavitt and A. M. Loyd. 2008. Regulation of the anthocyanin biosynthetic pathway by the TTG1/bHLH/Myb transcriptional complex in Arabidopsis. Plant J. 53: 814-827.

Hamada, Y., H. Sato, S. Otagaki, K. Okada, K. Abe and S. Matsumoto. 2015. Breeding depression of red flesh apple progeny containing both functional $M d M Y B 10$ and MYB110a_JP genes. Plant Breed. 134: 239-246.

Honda, C., H. Bessho, M. Murai, H. Iwanami, S. Moriya, K. Abe, M. Wada, Y. Moriya-Tanaka, H. Hayama and M. Tatsuki. 2014. Effect of temperature on anthocyanin synthesis and ethylene production in the fruit of early- and mediummaturing apple cultivars during ripening stages. HortScience 49: $1510-1517$.

Honda, C., H. Iwanami, K. Naramoto, T. Maejima, K. Kanamaru, Y. Moriya-Tanaka, T. Hanada and M. Wada. 2017. Thinning and bagging treatments and the growing region influence anthocyanin accumulation in red-fleshed apple fruit. Hort. J. 86: 291-299.

Honda, C., N. Kotoda, M. Wada, S. Kondo, S. Kobayashi, J. Soejima, Z. Zhang, T. Tsuda and T. Moriguchi. 2002. Anthocyanin biosynthetic genes are coordinately expressed during red coloration in apple skin. Plant Physiol. Biochem. 40: 955-962.

Hu, D., C. Sun, Q. Ma, C. You, L. Cheng and Y. Hao. 2016. MdMYB1 regulates anthocyanin and malate accumulation by directly facilitating their transport into vacuoles in apples. Plant Physiol. 170: 1315-1330.

Iamsub, K., Y. Sekozawa, S. Sugaya, H. Gemma and Y. Kamuro. 2009. Alleviating sunburn injury in apple fruit using natural and fertilizer forms of S-abscisic acid and its underlying mechanism. J. Food. Agric. Environ. 7: 446-452.

Iglesias, I., J. Bonany, I. Batlle, C. M. Cantín, M. Troggio, A. C. Allan, A. Friend, R. V. Espley, K. Lin-Wang, D. Chagné and R. K. Volz. 2016. The development of red-skinned apples adapted to the warm climates of South European countries. Chronica Hortic. 56: 9-14.

Iglesias, I., J. Salvía, L. Torguet and C. Cabús. 2002. Orchard cooling with overtree microsprinkler irrigation to improve 
fruit colour and quality of 'Topred Delicious' apples. Sci. Hortic. 93: 39-51.

Ireland, H. S., F. Guillen, J. Bowen, E. J. Tacken, J. Putterill, R. J. Schaffer and J. W. Johnston. 2012. Mining the apple genome reveals a family of nine ethylene receptor genes. Postharvest Biol. Technol. 72: 42-46.

Iwanami, H., Y. Moriya-Tanaka, T. Hanada, C. Honda and M. Wada. 2016. Labor-saving production of apple with red coloration and marked eating quality by effective use of a chemical defoliant. Hort. Res. (Japan) 15: 29-37 (In Japanese with English abstract).

Ji, X., R. Zhang, N. Wang, L. Yang and X. Chen. 2015. Transcriptome profiling reveals auxin suppressed anthocyanin biosynthesis in red-fleshed apple callus (Malus sieversii f. niedzwetzyana). Plant Cell Tiss. Organ Cult. 123: 389404.

Ju, Z., Y. Duan and Z. Ju. 1999. Effects of covering the orchard floor with reflecting films on pigment accumulation and fruit coloration in 'Fuji' apples. Sci. Hortic. 82: 47-56.

Ju, Z., C. Liu and Y. Yuan. 1995. Activities of chalcone synthase and UDPGal: Flavonoid-3-o-glycosyltransferase in relation to anthocyanin synthesis in apple. Sci. Hortic. 63: 175-185.

Ju, Z., Y. Yuan, C. Liu, Y. Wang and X. Tian. 1997. Dihydroflavonol reductase activity and anthocyanin accumulation in 'Delicious', 'Golden Delicious' and 'Indo' apples. Sci. Hortic. 70: 31-43.

Kondo, S., M. Maeda, S. Kobayashi and C. Honda. 2002. Expression of anthocyanin biosynthetic genes in Malus sylvestris L. 'Mutsu' non-red apples. J. Hort. Sci. Biotech. 77: 718-723.

Koshiyama, M., H. Seto, Y. Kamuro, K. Watanabe, M. Mitomi and K. Imamura. 2003. A jasmonic acid analog, PDJ, comes into practical use as a plant growth regulator. Plant Growth Regul. 38: 47 (In Japanese with English abstract).

Kunihisa, M., S. Moriya, K. Abe, K. Okada, T. Haji, T. Hayashi, H. Kim, C. Nishitani, S. Terakami and T. Yamamoto. 2014. Identification of QTLs for fruit quality traits in Japanese apples: QTLs for early ripening are tightly related to preharvest fruit drop. Breed. Sci. 64: 240-251.

Larrigaudiere, C., E. Pinto and M. Vendrell. 1996. Differential effects of ethephon and seniphos on color development of 'Starking Delicious' apple. J. Amer. Soc. Hort. Sci. 94: 193199.

Li, Y., K. Mao, C. Zhao, X. Zhao, H. Zhang, H. Shu and Y. Hao. 2012. MdCOP1 ubiquitin E3 ligases interact with MdMYB1 to regulate light-induced anthocyanin biosynthesis and red fruit coloration in apple. Plant Physiol. 160: 1011-1022.

Lin-Wang, K., K. Bolitho, K. Grafton, A. Kortstee, S. Karunairetnam, T. K. McGhie, R. V. Espley, R. P. Hellens and A. C. Allan. 2010. An R2R3 MYB transcription factor associated with regulation of the anthocyanin biosynthetic pathway in Rosaceae. BMC Plant Biol. 10: 50.

Lin-Wang, K., D. Micheletti, J. Palmer, R. Volz, L. Lozano, R. Espley, R. P. Hellens, D. Chagné, D. D. Rowan, M. Troggio, I. Iglesias and A. C. Allan. 2011. High temperature reduces apple fruit colour via modulation of the anthocyanin regulatory complex. Plant Cell Environ. 34: 1176-1190.

Mazza, G. and E. Miniati. 1993. Introduction, IV. Biosynthesis. p. 20-21; Pome Fruit, I. Apple. p. 29-31. In: Anthocyanins in Fruits, Vegetables, and Grains. CRC press, Boca Raton.

Mazza, G. and Y. S. Velioglu. 1992. Anthocyanins and other phenolic compounds in fruits of red-flesh apples. Food Chem. 43: 113-117.

Moriya, S., M. Kunihisa, K. Okada, T. Shimizu, C. Honda, T. Yamamoto, H. Muranty, C. Denance, Y. Katayose, H. Iwata and K. Abe. 2017. Allelic composition of MdMYB1 drives red skin color intensity in apple (Malus $\times$ domestica Borkh.) and its application to breeding. Euphytica 213: 78.

Neilsen, G. H., D. Neilsen and L. Herbert. 2009. Nitrogen fertigation concentration and timing of application affect nitrogen nutrition, yield, firmness, and color of apples grown at high density. HortScience 44: 1425-1431.

Peng, T., T. Saito, C. Honda, Y. Ban, S. Kondo, J. Liu, Y. Hatsuyama and T. Moriguchi. 2013. Screening of UV-Binduced genes from apple peels by SSH: Possible involvement of MdCOP1-mediated signaling cascade genes in anthocyanin accumulation. Physiol. Plant. 148: 432-444.

Rudell, D. R., J. K. Fellman and J. P. Mattheis. 2005. Preharvest application of methyl jasmonate to 'Fuji' apples enhances red coloration and affects fruit size, splitting, and bitter pit incidence. HortScience 40: 1760-1762.

Rupasinghe, H. P. V., G. M. Huber, C. Embree and P. L. Forsline. 2010. Red-fleshed apple as a source for functional beverages. Can. J. Plant Sci. 90: 95-100.

Sadilova, E., F. C. Stintzing and R. Carle. 2006. Chemical quality parameters and anthocyanin pattern of red-fleshed Weirouge apples. J. Appl. Bot. Food Qual. 80: 82-87.

Salvatierra, A., P. Pimentel, M. A. Moya-León and R. Herrera. 2013. Increased accumulation of anthocyanins in Fragaria chiloensis fruits by transient suppression of FcMYB1 gene. Phytochemistry 90: 25-36.

Sato, H., S. Otagaki, P. Saelai, A. Kodo, K. Shirataki and S. Matsumoto. 2017. Varietal differences in phenolic compounds metabolism of type 2 red-fleshed apples. Sci. Hortic. 219: 1-9.

Saure, M. C. 1990. External control of anthocyanin formation in apple. Sci. Hortic. 42: 181-218.

Stern, R., R. Korchinsky, R. Ben-Arie and Y. Cohen. 2010. Early application of the synthetic auxin 2,4-DP enhances the red colouration of 'Cripp's Pink' apple. J. Hort. Sci. Biotech. 85: 35-41.

Sun, J., Y. Wang, X. Chen, A. Gong, N. Wang, L. Ma, Y. Qiu, Y. Wang and S. Feng. 2017. Effects of methyl jasmonate and abscisic acid on anthocyanin biosynthesis in callus cultures of red-fleshed apple (Malus sieversii f. niedzwetzyana). Plant Cell Tiss. Organ Cult. 130: 227-237.

Takos, A. M., F. W. Jaffé, S. R. Jacob, J. Bogs, S. P. Robinson and A. R. Walker. 2006. Light-induced expression of a MYB gene regulates anthocyanin biosynthesis in red apples. Plant Physiol. 142: 1216-1232.

Ubi, B. E. 2004. External stimulation of anthocyanin biosynthesis in apple fruit. Food Agric. Environ. 2: 65-70.

Ubi, B. E., C. Honda, H. Bessho, S. Kondo, M. Wada, S. Kobayashi and T. Moriguchi. 2006. Expression analysis of anthocyanin biosynthetic genes in apple skin: Effect of UVB and temperature. Plant Sci. 170: 571-578.

Umemura, H., S. Otagaki, M. Wada, S. Kondo and S. Matsumoto. 2013. Expression and functional analysis of a novel $M Y B$ gene, MdMYB110a_JP, responsible for red flesh, not skin color in apple fruit. Planta 238: 65-76.

Velasco, R., A. Zharkikh, J. Affourtit, A. Dhingra, A. Cestaro, A. Kalyanaraman, P. Fontana, S. K. Bhatnagar, M. Troggio, D. Pruss, S. Salvi, M. Pindo, P. Baldi, S. Castelletti, M. Cavaiuolo, G. Coppola, F. Costa, V. Cova, A. Dal Ri, V. Goremykin, M. Komjanc, S. Longhi, P. Magnago, G. Malacarne, M. Malnoy, D. Micheletti, M. Moretto, M. Perazzolli, A. Si-Ammour, S. Vezzulli, E. Zini, G. Eldredge, L. M. Fitzgerald, N. Gutin, J. Lanchbury, T. Macalma, J. T. Mitchell, J. Reid, B. Wardell, C. Kodira, Z. Chen, B. Desany, F. Niazi, M. Palmer, T. Koepke, D. Jiwan, S. Schaeffer, V. Krishnan, C. Wu, V. T. Chu, S. T. King, J. 
Vick, Q. Tao, A. Mraz, A. Stormo, K. Stormo, R. Bogden, D. Ederle, A. Stella, A. Vecchietti, M. M. Kater, S. Masiero, P. Lasserre, Y. Lespinasse, A. C. Allan, V. Bus, D. Chagne, R. N. Crowhurst, A. P. Gleave, E. Lavezzo, J. A. Fawcett, S. Proost, P. Rouze, L. Sterck, S. Toppo, B. Lazzari, R. P. Hellens, C. E. Durel, A. Gutin, R. E. Bumgarner, S. E. Gardiner, M. Skolnick, M. Egholm, Y. Van de Peer, F. Salamini and R. Viola. 2010. The genome of the domesticated apple (Malus $\times$ domestica Borkh.). Nature Genet. 42: 833-839.

Vimolmangkang, S., D. Zheng, Y. Han, M. A. Khan, R. E. SoriaGierra and S. S. Korban. 2014. Transcriptome analysis of the exocarp of apple fruit identifies light-induced genes involved in red color pigmentation. Gene 534: 78-87.

Volz, R. K., S. Kumar, D. Chagné, R. Espley, T. K. McGhie and A. C. Allan. 2013. Genetic relationship between red flesh and fruit quality traits in apple. Acta Hortic. 976: 363-368.

Volz, R. K., N. C. Oraguzie, C. J. Whitworth, N. How, D. Chagné, C. M. Carlisle, S. E. Gardiner, E. H. A. Rikkerink and T. Lawrence. 2009. Breeding for red flesh colour in apple: Progress and challenges. Acta Hortic. 814: 337-342.

Wang, H. and L. Cheng. 2011. Differential effects of nitrogen supply on skin pigmentation and flesh starch breakdown of 'Gala' apple. HortScience 46: 1116-1120.

Wang, Z. and D. R. Dilley. 2001. Aminoethoxyvinylglycine, combined with ethephon, can enhance red color develop- ment without over-ripening apples. HortScience 36: 328 331.

Whale, S. K. and Z. Singh. 2007. Endogenous ethylene and colour development in the skin of 'Pink Lady' apple. J. Amer. Soc. Hort. Sci. 132: 20-28.

Wojdyło, A., J. Oszmiański and P. Laskowski. 2008. Polyphenolic compounds and antioxidant activity of new and old apple varieties. J. Agric. Food Chem. 56: 6520-6530.

Xie, X. B., S. Li, R. F. Zhang, J. Zhao, Y. C. Chen, Q. Zhao, Y. X. Yao, C. X. You, X. S. Zhang and Y. J. Hao. 2012. The bHLH transcription factor MdbHLH3 promotes anthocyanin accumulation and fruit colouration in response to low temperature in apples. Plant Cell Environ. 35: 1884-1897.

Yuan, K. J., C. J. Wang, J. H. Wang, L. Xin, G. F. Zhou, L. G. Li and G. N. Shen. 2014. Analysis of the MdMYB1 gene sequence and development of new molecular markers related to apple skin color and fruit-bearing traits. Mol. Genet. Genomics 289: 1257-1265.

Zhang, X. J., L. X. Wang, X. X. Chen, Y. L. Liu, R. Meng, Y. J. Wang and Z. Y. Zhao. 2014. A and MdMYB1 allele-specific markers controlling apple (Malus $\times$ domestica Borkh.) skin color and suitability for marker-assisted selection. Gen. Mol. Res. 13: 9103-9114.

Zhu, Y. M., K. Evans and C. Peace. 2011. Utility testing of an apple skin color MdMYB1 marker in two progenies. Mol. Breed. 27: 525-532. 